\title{
Breeding of captive bank voles (Clethrionomys glareolus) related to dynamics of source populations
}

\author{
L. Hansson \\ Department of Wildlife Ecology, Swedish University of Agricultural Sciences, S-750 07 Uppsala, \\ Sweden
}

\begin{abstract}
Summary. Proportionately fewer female bank voles from cyclic or dense populations bred than did females from sparse or non-cyclic populations when brought into a laboratory and kept as monogamous pairs for at least 1 year. Similarly, fewer litters were produced by females from cyclic or dense populations. Breeding frequency and litter production did not differ in the second laboratory generation. Large variance in litter numbers indicated further changes in reproduction in response to the laboratory environment. Certain differences between origins still persisted after long-term laboratory breeding. The regional variations between field-born animals are most parsimoniously explained by differences in sensitivity to density.
\end{abstract}

Keywords: bank vole; breeding frequency; litter numbers; population density

\section{Introduction}

Breeding intensity varies with population phase in cyclic microtines, such as northern bank voles, Clethrionomys glareolus (see Hansson \& Henttonen, 1985a). Overwintered females and those born in that year breed in populations that increase in numbers, sometimes even in the mid-winter; the former females usually produce just 1 or 2 litters in populations with peak numbers and the yearborn animals then produce none. Animals in non-cyclic populations of bank voles breed from about April to September each year and year-born females mature and regularly breed in late summer (Nyholm \& Meurling, 1979).

Bank voles brought into laboratories and kept on suitable food have shown differences in various aspects of reproduction depending on the place of origin (Gustafsson et al., 1983a; Hansson \& Henttonen, 1985a; Ebenhard, 1987). Generally north Swedish animals from cyclic populations produce more young per litter than do south Swedish animals from non-cyclic populations, yet fewer mature females from the cyclic populations produce young. These observations come from animals bred for various numbers of generations in captivity. However, the studies by Hansson \& Henttonen (1985a) indicated a large change in reproductive patterns between the first and second generation in captivity. No reasonable explanation has been provided for these patterns.

In the present study I have compared other Swedish localities with different dynamics, and especially consider females brought into the laboratory from the field. The main question asked is: do different population densities select for females with specific reproductive characteristics?

\section{Material and Methods}

Immature bank voles (Clethrionomys glareolus) were caught in the 1980s in early autumn (September-early October) at Revinge $\left(56^{\circ} \mathrm{N}\right)$, Uppsala $\left(60^{\circ} \mathrm{N}\right)$, on the island of Valen within the Uppsala region, and at Stromsund $\left(64^{\circ} \mathrm{N}\right)$. The voles at Revinge are non-cyclic, those at Uppsala only faintly cyclic while voles at Strömsund show a pronounced cyclicity (Hansson \& Henttonen, 1985b). Annual variations were 10-100 times larger in cyclic than non-cyclic populations but long-term mean densities did not differ much for the populations with the two types of dynamics 
(Angelstam et al., 1987). The bank vole population on Valen island, with few predators, reached very high autumn densities each year during the period 1987-89 when neighbouring populations peaked and crashed (B. Martinsson, L. Hansson \& P. Angelstam, unpublished).

The animals were kept as monogamous pairs in laboratory mouse cages at $20^{\circ} \mathrm{C}$ and in natural light at Uppsala. Laboratory mouse pellets and water were given ad libitum. The voles were retained until the end of September the following year or, if they produced a litter in that month, until reproduction ended. Young of these animals, born in late summer-early autumn, were paired randomly between families of the same provenance and treated in the same way. The number of litters and young born were established for each female. Young were weaned at 20 days of age.

\section{Results}

The females from the different sources showed only random variations between years in the proportion producing at least one litter (Table 1). Although 1983 and 1986 were pronounced increase years at Strömsund and 1980 and 1987 were peak-decline years (Hansson, 1987, 1988), these years did not differ significantly in the frequency of reproducing females. Thus, the total material from all years could be pooled for each locality.

Table 1. Breeding $(1+$ litters) and non-breeding ( 0 litters) bank vole females in those brought to the Uppsala laboratory from four different localities during various years

\begin{tabular}{lccccccccc}
\hline & & \multicolumn{8}{c}{ Years } \\
\cline { 3 - 10 } Locality & Litters & 1980 & 1981 & 1982 & 1983 & 1986 & 1987 & 1988 & Total \\
\hline Revinge & $1+$ & 8 & 4 & 6 & 5 & 1 & 7 & 3 & 34 \\
& 0 & 3 & 7 & 4 & 5 & 3 & 4 & 3 & 29 \\
Uppsala & $1+$ & 1 & - & 4 & 1 & 2 & 4 & 6 & 18 \\
\multirow{2}{*}{ Valen } & 0 & 1 & - & 3 & 4 & 0 & 7 & 9 & 24 \\
\multirow{3}{*}{ Strömsund } & $1+$ & - & - & - & - & - & 0 & 1 & 1 \\
& 0 & - & - & - & - & - & 4 & 10 & 14 \\
& $1+$ & 2 & 2 & 0 & 2 & 2 & 2 & - & 10 \\
& 0 & 10 & 6 & 1 & 8 & 8 & 5 & - & 38 \\
\hline
\end{tabular}

The first generation females showed a significant difference in proportions reproducing (Table $1, \mathrm{G}=21.51, P<0.001)$. However, the Revinge and Uppsala animals did not differ significantly and nor did those of Valen and Strömsund. The difference was therefore between the sparse and constant density populations from Revinge and Uppsala and the dense or cyclic populations at Valen and Strömsund, with a much larger proportion of females from the first two localities reproducing in captivity.

Second generation females, with 15 reproducing out of 36 Revinge animals, 4 reproducing out of 8 Uppsala animals and 15 reproducing out of 27 Strömsund animals, did not differ between origins in the proportion reproducing. The mean value $(48 \%)$ was very close to the mean value for Revinge + Uppsala wild-caught females $(50 \%)$.

The number of litters per first generation female differed significantly between the three main localities (Valen, from which only one female reproduced, was excluded), with a larger number of litters in Revinge females than in females from the two more cyclic populations (Table 2). The second generation females did not differ between provenances with regard to mean number of litters (Table 2), but showed a much higher variance than the first generation.

The number of young per litter has been examined earlier for first and second generation females from Revinge and Strömsund (see Hansson \& Henttonen, 1985a) and found not to differ significantly. However, the mean values were higher in Strömsund animals, especially in the second generation. 
Table 2. Number of litters per female in first and second generation bank voles from three Swedish localities

\begin{tabular}{|c|c|c|c|c|c|c|}
\hline \multirow[b]{2}{*}{ Locality } & \multicolumn{3}{|c|}{ First generation* } & \multicolumn{3}{|c|}{ Second generation $\dagger$} \\
\hline & No. & Mean & s.d. & No. & Mean & s.d. \\
\hline Revinge & 34 & $5 \cdot 7$ & $2 \cdot 0$ & 15 & $5 \cdot 6$ & $3 \cdot 2$ \\
\hline Uppsala & 18 & $4 \cdot 5$ & 1.9 & 4 & $5 \cdot 0$ & $5 \cdot 0$ \\
\hline Strömsund & 10 & $4 \cdot 3$ & $2 \cdot 2$ & 15 & $5 \cdot 4$ & 3.9 \\
\hline
\end{tabular}

\section{Discussion}

Wild animals differed clearly between localities but not within years. Females from two localities with annual (Valen) or temporary (Strömsund) very high densities showed considerably lower frequencies of litter production, measured either as reproducing animals or litters per female. The variation was not related to cycle phase or affected by the slight or temporary cyclicity observed at Uppsala, and so it cannot be explained by phase-dependent polymorphism (the Chitty Hypothesis: Krebs, 1978).

Litter sizes have been found to be larger in animals from northern or cyclic populations, both in the field (Hansson, 1969; Gustafsson, 1983; Hansson \& Henttonen, 1985a) and after long-term laboratory breeding (Gustafsson, 1983; Ebenhard, 1987). However, the latter difference was found after many generations of laboratory breeding and may develop eventually in Strömsund animals. In any case, it was not a part of the main change between first and second generation animals.

The animals reproducing in captivity may have been especially 'tame' and not sensitive to the strange environment or the proximity of a large number of conspecifics, e.g. the constant presence of one male and odour from other males and females. Such characteristics of domestication may have been selected for in bank voles as well as in a large number of other laboratory and domestic animals (see Price \& King, 1968). Clarke $(1977,1985)$ summarized evidence for genetic variation in reproductive traits between various field populations of bank voles. However, his evidence from long-term laboratory breeding suggested that separate populations were genetically fairly homogeneous. This study indicates that bank voles from dense populations contain a larger proportion of animals sensitive to crowding or new environments. Second generation females produced a very variable number of litters, and fecund females are likely to be 'selected' by breeders, leading to rapid evolution of 'laboratory genotypes'. However, these final laboratory types still differ between provenances with respect to at least body size (Hansson, 1985) and litter size (see above).

There are also other characteristics of cyclic animals which separate them from non-cyclic ones when kept in constant laboratory environments. Cyclic bank voles redistribute stores in a conspicuous way when confronted with an intruder while this is not obvious in non-cyclic animals; non-cyclic animals seem more sociable (Hansson, 1986). Cyclic voles, both bank voles (Hansson, 1985) and field voles, Microtus agrestis (Nygren, 1978), are more active than non-cyclic ones. Cyclic voles in the laboratory show a higher level of social suppression of sexual maturation than do noncyclic ones (Gustafsson et al., 1983b). A syndrome of fierce and 'nervous' behaviour components therefore seems to be selected for in high density populations. This may be reflected in the shortened reproductive seasons of voles in cyclic peak phases. It is unclear whether this behaviour is selected in increase (Cockburn, 1988) or peak (Krebs, 1978) phases but it is obviously retained over all the cycles.

This study was supported by grants from the Swedish Natural Science Research Council. I thank Andrew Cockburn for comments. 


\section{References}

Angelstram, P., Hansson, L. \& Pehrsson, S. (1987) Distribution borders of field mice Apodemus: the importance of seed abundance and landscape composition. Oikos 50, 123-130.

Clarke, J.R. (1977) Long and short term changes in gonadal activity of field voles and bank voles. Oikos 29, 457-467.

Clarke, J.R. (1985) The reproductive biology of the bank vole (Clethrionomys glareolus) and the wood mouse (Apodemus sylvaticus). Symp. zool. Soc. London 55, 33-59.

Cockburn, A. (1988) Social Behaviour in Fluctuating Populations. Croom Helm, London.

Ebenhard, T. (1987) An experimental test of the island colonization survival model: bank vole (Clethrionomys glareolus) populations with different demographic parameter values. J. Biogeogr. 14, 213-223.

Gustafsson, T.O. (1983) Reproduction and social regulation of sexual maturation in relation to population cyclicity in bank voles, Clethrionomys glareolus. Thesis, University of Lund.

Gustafsson, T.O., Andersson, C.B. \& Westlin, L. (1983a) Reproduction in laboratory colonies of bank vole, Clethrionomys glareolus, originating from populations with different degrees of cyclicity. Oikos $\mathbf{4 0}$, $182-188$.

Gustafsson, T.O., Andersson, C.B. \& Nyholm. N.E.I. (1983b) Comparison of sensitivity to social suppression of sexual maturation in captive male bank voles, Clethrionomys glareolus, originating from populations with different degrees of cyclicity. Oikos 41, $250-254$.

Hansson, L. (1969) Spring populations of small mammals in central Swedish Lapland in 1964-68. Oikos 20, $431-450$.
Hansson, L. (1985) Geographic differences in bank voles Clethrionomys glareolus in relation to ecogeographic rules and possible demographic and nutritive strategies. Annls Zool. Fenn. 22, 319-328.

Hansson, L. (1986) Geographic differences in the sociability of voles in relation to cyclicity. Anim. Behav. 34, 1215-122I.

Hansson, L. (1987) An interpretation of rodent dynamics as due to trophic interactions. Oikos 50, 308-318.

Hansson, L. (1988) Grazing impact by small rodents in a steep cyclicity gradient. Oikos 51, 31-42.

Hansson, L. \& Henttonen, H. (1985a) Regional differences in cyclicity and reproduction in Clethrionomys species: are they related? Annls Zool. Fenn. 22, $277-288$.

Hansson, L. \& Henttonen, H. (1985b) Gradients in density variations of small rodents: the importance of latitude and snow cover. Oecologia (Berl.) 67, 394402.

Krebs, C.J. (1978) A review of the Chitty Hypothesis of population regulation. Can. J. Zool. 56, 2463-2480.

Nygren, J. (1978) Interindividual influence on diurnal rhythms of activity in cycling and noncycling populations of the field vole, Microtus agrestis L. Oecologia (Berl.) 35, 231-239.

Nyholm, N.E.I. \& Meurling, P. (1979) Reproduction of the bank vole, Clethrionomys glareolus, in northern and southern Sweden during several seasons and in different phases of the vole population cycle. Holarct. Ecol. 2, 12-20.

Price, E.O. \& King, J.A. (1968) Domestication and adaptation. In Adaptation of Domestic Animals, pp. 34-45. Ed. E. S. E. Hafez. Lea \& Febiger, Philadelphia.

Received 15 January 1990 